\title{
A Study on the Application of Schema Theory to English Newspaper Reading*
}

\author{
Yunning Che \\ The School of Foreign Languages, Qingdao University of Science and Technology, China
}

\begin{abstract}
Reading is one of the essential skills for human beings in language learning and it plays a very important role in the work and life of human beings. Schema is the mental structures which store our knowledge, while the theory of comprehension based on schema is called schema theory. According to the Schema theories, reading comprehension is an interactive process between the reader and the text, which is mainly affected by the readers' background knowledge. The Schema theory indicates that the comprehension of a reader about a text is determined by the three schemas: language schema, content schema and formal schema. This case study with the guiding of the Schema theory applied in newspaper reading in the paper proves that without a proper schema, a reader cannot understand a text; even with the proper schemas, a reader might fail to understand the text for the author doesn't provide enough clues for readers to activate the schemas that the reader has.
\end{abstract}

Index Terms — bottom-up model, top-down model, schema theory, English newspaper reading

\section{INTRODUCTION}

English reading is one of the most important courses in not only middle schools but also in colleges and universities. Reading comprehension is one of the essential abilities required in English study and one important part in English teaching. So the improving of the students' reading comprehension is one of the main tasks in English teaching. In traditional English reading classes, the students are usually assigned to preview the new words in the passages to be studied and read the passage in the class and then answer the questions following each of the passage. While the teachers' task is to urge the students to finish the reading in time and check the answers with them. Thus the efficiency of reading is mainly on the answer-check and the comprehension purpose of reading has been totally forgotten.

The term schema was firstly found in the works of some ancient philosophers and psychologists. In 1800s, Immanuel Kant summarized the philosophy sense of schema as the bridge conjoining concepts and the perceived objects. Later, it is believed that the process of telling stories is an imaginative reconstruction of the existing schemas and is the linking of the preexisting schemas with the new knowledge. With the development of the study of many psychologists and linguists, many of the traditional ideas and psychological thoughts have been absorbed and integrated into the theory of schema in modern time and achievements in this field have been increasingly made.

According to the Schema theories, readers possess different conceptual frameworks which they bring to the reading of a text and which they use to make sense of what they read. Researchers argued that schemas are the general knowledge people use to make sense of what they need. There are a variety of schemas in one's mind. The motivation of the schemas in a reader's mind helps to improve his/her reading comprehension. Based on the researches of the application of the Schema theory to reading, the psychologists and linguists (Carrel\& Eisterhold, 1983) found that the schema theory plays a guiding role in English reading comprehension.

\section{The Theoretical Development of Reading Studies}

Reading is one of the essential skills for human beings in language learning and it plays a very important role in the work and life of human beings. Before 1970s, reading was considered to be a process of language encoding and a creation of meaning from words, phrases and sentences. (Zhao, 2001, p.189)

Goodman(1975, p.135) stated that "reading is a psycholinguistic process by which the reader, a language user, reconstructs as best as he/she can a message which has been encoded by a writer as a graphic display". Later he presented another idea arguing that "reading is a receptive language process. It is a psycholinguistic process in that it starts with a linguistic surface representation encoded by a writer and ends with meaning which the reader constructs. There is thus an essential interaction between language and thought in reading. The writer encodes thought as language and the reader decodes language to thought."

According to Rumelhart (1977, p.88), reading is a "perceptual" and a "cognitive" process of understanding written language, and bridging and blurring these two traditional distinctions. Walker thinks that reading is an active process (not a product, like history) in which readers shift between sources of information (what they know and what the text

\footnotetext{
* Supported by the Social Science Foundation of Qingdao University of Science and Technology (NO. 0059241,10XC22)
} 
says), elaborate meaning and strategies, check their interpretation (revising when necessary) and use the social context to focus their response. Nuttal (2000, p.3) later presented his view that reading is essentially concerned with meaning, specifically with the transfer of meaning from mind to mind: the transfer of a message from writer to reader.

Although the above scholars defined reading in different ways, they agree on the same point that reading comprehension has much more to do with the readers' background knowledge than it does with the printed words. It can be thus concluded that reading comprehension is an interactive process between the reader and the text, which is mainly affected by the readers' background knowledge. Thorndike (1971, p.8) summarized certain significant processes associated with compression "Understanding a paragraph is like solving a problem in mathematics. This process consists of selecting the right elements of the situation, putting them together in amount of weight or influence or force to each. The mind is assailed as it were, by every word in the paragraph. It must select, repress, soften, emphasize, correlate and organize, all under the influence of the right mental set of purpose or demand." Thus reading comprehension becomes a process of both getting meaning form a passage and bringing meaning from a passage. On the one hand, the authors deliver information to the outside world through the printed words. On the other hand, the readers get information from the material he/she reads, and then process the information of the material. Thus different readers might understand the same information differently, which will be greatly depending on the readers' comprehension ability, cultural level, related background knowledge and many other factors.

Over the study of reading comprehension process, three models have been put forward to interpret it: bottom-up model, top-down model and interactive model.

\section{A. Bottom-up Model}

Defining that reading is a hierarchically organized (letter $\rightarrow$ word $\rightarrow$ sentence $\rightarrow$ text level)process, the Bottom-up Model(Gough,1972) emphasizes the knowledge of a language and thinks that reading is only a process of recognizing the low level structures and features of words and grammar in a text. The term "Bottom-up" is used because the reader begins from the bottom of the text in the reading process. According to this model, reading is a process of constructing symbol into words, words into sentences, and sentences into the whole meaning. The reader begins with the written text (the bottom), and constructs meaning from the letters, words, phrases, and sentences found within and then processes the text in a series of discrete states in a linear fashion (Barnett, 1989). Under the influence of the Bottom-up Model, it is believed in the traditional teaching that the main obstacle of reading for students is the language itself and thus the primary task for the teachers is to help the students get rid of the possible language problems. So in English reading classes, teachers applying Bottom-up Model tend to analyze the text word by word, sentence by sentence until small chunks of text become meaningful. But because too much of the focus is on the language points, the reading speed are unavoidably affected, which is the main deficiency of the Bottom-up Model. The Bottom-up Model makes reading a passive process of decoding a series of English written symbols into Chinese equivalents. It is thus believed that the core of the Bottom-up Model is that it emphasizes a single-direction, part-to-whole processing of a text and it gives little emphasis to the influences of the readers' world knowledge, contextual information, and other higher-order processing strategies.

\section{B. Top-down Model}

From the end of 1960 s to the beginning of 1970 s, combined with the psychology theories, K.S.Goodman, H.K.Smith et al. pointed out that non-language factors also play parts in improving one's reading abilities, based on which the Top-down Model was put forward. The Top-down Model claimed that reading is a process of the interaction between language and thought. According to this model, reading is a psycholinguistic guessing game (Goodman, 1967) in which "efficient readers minimize dependence on visual detail" by utilizing background knowledge to make predictions and checking these against the text (Goodman, 1975, p.12). This model is also called reader-driven model. According to Goodman (1967), readers predict and anticipate the incoming information on the basis of the syntactic and semantic information, sample from the print just enough to confirm or reject their guesses of what is coming. In another word, the more one knows the theme of a text, the better one can understand it. The readers use their knowledge of the world to make guesses about what might come next in the text. They form hypothesis about the text and then use the text data to confirm or deny their hypothesis. According to Anderson (2000), reading comprehension is an active process in which readers not only apply their knowledge of language, but also call upon their previous experience and general knowledge of the world.

However, such Top-down Model has unfortunately given the misleading message to teachers that ESL reading tuition is "mostly just a matter of providing [learners] with the right background knowledge... and encouraging them to make full use of that knowledge in decoding... texts" (Eskey, 1988, p.97). Once the text is unfamiliar to the readers or the language is too obscure, the comprehension of the text will be greatly affected.

\section{Interactive Model}

Based on the above discussion, we can find that both the Bottom-up Model and the Top-down Model have their own disadvantages. The Bottom-up Model has failed to recognize the role of higher order knowledge while the Top-down Model does not recognize the importance of lower level process. The Interactive Model emphasizes a two-way transmission of information. According to Rumelhart (1977), reading is a cognitive and perceptual process, which 
bridges and blurs both two traditional approaches. A skilled reader is able to make use of semantic, syntactic, sensory and pragmatic information to comprehend the reading material. In this process, both lower-level and higher-level process work interactively and successful readers continue to make use of cues at all levels, from graphic to schematic.

\section{Schema Theory and Schema}

Overcoming the deficiencies of both the Bottom-up Model and the Top-down Model, the Schema theory combines these two models effectively and indicates that reading is a process of the double effects of the two models or the interaction between one's background knowledge and the text. Nunan (1999) argues that schema is the mental structures which store our knowledge, while the theory of comprehension based on schema is called schema theory.

The term "schema" was firstly proposed by Barnett (1989, p.77), who defines it as "an active organization of pass reactions, or past experience". A schema is an organized, general knowledge about situations and individuals that has been abstracted from prior experiences and stored in long term memory. Schemas change, develop and interact and arise in response to new situation. Rumelhart (1977, p.96) summarized schema as "sets of interactive knowledge structure" or "the building of blocks of cognition". Carrell $(1983$, p.82) states that " the prior knowledge of the reader is organized as his/her schema, which is usually viewed as hierarchically arranged into various subsets of placeholders within more general or higher-order schema. In people's minds, there are different kinds of schemas, for instance, schema on restaurants, schema on music.

The Schema theory indicates that the comprehension of a reader about a text is determined by the three schemas: language schema, content schema and formal schema. Language schemas refer to the degree a reader possesses the language of the text emphasizing the effect of background knowledge in the macroscopic side and the linguistic factors in the microcosmic side; Content schemas involve the familiarity of a reader with the theme or the background knowledge of the text. Some researchers argue that: if people lack the content schemas or the capacity of allocating schemas, they will have difficulties in building hypothesis and reading although they have specified capacity of language; and the formal schemas are the degree of a reader's knowledge on the style of the text, i.e. the readers have to distinguish the different styles, pages and structures. Therefore, it is quite necessary for us to pay attention to the materials that have different styles, pages and structures. Among these three schemas, the language schema acts as the basis of the other two schemas and the three decide the comprehending ability of the readers by interacting with each other. Since schemas are formed on the basis of one's experiences, different readers might have different schemas and thus there might be different understanding of a text. In general, the more complete one's three schemas for information, the faster one will read and the better one may comprehend. On the contrary, the absence of proper schemas or the inadequate clues to activate the existing schemas or the inability to link to the existing schemas might result in misunderstanding of the text or bewilderment in reading. So do schemas have any influence on one's English reading comprehension? Here in the following is a case study to test it.

\section{A CASE STUDY}

1. The purpose: to test whether schemas influence one's reading comprehension of English newspaper.

2. Method

2.1 Subjects

36 sophomores majored in English from three classes, and their grades in TEM 4 (Test for English Majors Band 4) are similar and none of them have ever read any of the news given to them or have been trained with the knowledge of newspaper reading before. They were divided equally into two groups: Group A and Group B, among which A is the experimental group and B is the control group.

\subsection{Materials}

Three pieces of English news have been chosen and 15 multiple-choice questions were designed. The questions are not only about the theme of the articles and the ideas of the author, but the details of the articles. For example, questions about some words or sentences of the articles.

\subsection{Procedure}

The task and teaching method for these two groups are different. Before reading the three articles, Group A received some training courses of newspaper reading according to the contents of the reading materials and was introduced briefly about the style of English news writing and wording. The purpose of the training is to form and activate the students the schemas of English news knowledge. Group B was given no instruction before reading. The length of reading time for Group A and Group B was the same. After reading, the teachers checked the answers and interviewed the students about the reasons for their choice.

\section{Activity 1: Getting to know the newspaper-----improving the formal schema}

Give students in Group A a copy of newspaper, which serves as the introductory activity aimed at the dual purpose of familiarizing students with the outlay of the news via the exploitation of reading strategies and skills such as reading rate and scanning in particular. Before the reading, the teacher will tell the students about the structure arrangement of news. After scanning the news, the students are required to write down the theme.

\section{Activity 2: Word building game---improving the language schema}

In this part, students can work individually or in pairs to pick out as many new words as they can from it within a 
certain time limit. Those/He/She who get(s) the largest number of new words are/is declared the winner. Then ask each of the students to underline any of the difficult word and encourage them to make a logical guess at the meaning based on the contextual clues. After that, they will be permitted to refer to the dictionary to see if their guess is right. For some of the other new words for students, the teacher provides the meaning of them used in a specific news item. Students skim the news and scan to locate the words that match the meanings provided. The games above will generate the excitement and a sense of competition of the students.

\section{Activity 3: Working with headlines---improving the content schema}

In this part, a number of activities are employed in the class for Group A students. Since the headline is often not very clear by the virtue of the telegraphic style, the teacher then explains the functions of headlines and set them tasks in different ways. Five kinds of tasks are set: 1) To form complete sentence(s) from the headlines on the newspaper; 2) To match the news with the headlines. In this part, the news and their headlines are put out of their original order. Half of the students are provided with the headlines and half with the news. After finishing their reading within a time limit, they move around for possible matches. During this process, they are not allowed to refer to any words or terms. But they are encouraged to hold discussions before they make the match. 3) To predict news report/headline. Give half of the students in Group A the headlines only to ask them to make up brief news reports to match the headlines. And another half of the students with the news clipping are asked to work out simple headlines. After that, they may check the actual versions found in the newspaper and see how close their interpretations are. This activity helps to improve the students' abilities of anticipation and prediction through logical thinking. 4) To rearrange cut-out words to form headlines. Two students in a pair are provided with an envelop containing cutup words, which they must rearrange to form headlines within a limited time. 5) To use headlines to express feelings and attitudes. Ask some of the students to bring to the class some clippings of headlines and read them out to the other students in the class. Then ask the students who listen to them to express their feelings upon hearing the headlines. The news item can be classified under "good news", "bad news". Then students are required to encode this feeling in a written or spoken way.

Having finished the above activities, the students in Group A are required to read the three pieces of news provided for both Group B and them. And then answer the questions within the limited time. At the same time, students in Group $\mathrm{B}$ are also working on the same reading. The teachers check the answers when both Group A and Group B hand in their answers.

2.4 The experiment result

Group A (18 students) accuracy: $80 \%$

Group B (18 students) accuracy: $41 \%$

In the interview, students in Group A provided adequate reasons for their choices and are found to be more easily to connect what they have learnt in the training with the contents of the texts. They could even discuss about the contents and choices with the teachers actively. While students in Group B were more likely to guess the answers and most of them said that the articles were too difficult for them and they knew so little about English news structure and features. Some even said that they were of no interest in this type of articles.

The experiment result shows that the teaching method of schema activation played a great role in promoting the students' reading comprehension, which is mainly reflected in the following aspects:

(1) The schema method can help the students form or activate the schemas about the reading texts in a short time and improve their reading comprehension and thus arouse the interest of the students in the texts, which, before the formation of the schemas or activation of the schemas, might be the fields the students know nothing about or have no interest in.

(2) By comparing the experiment results of the two groups, it can be found that the main reason for the difference of the experiment results is the lack of schemas of the text, or in another word, the lack of the background information of the text. Besides, vocabulary is another obstacle for the students. If the students do not have the background knowledge of the text or the clues to understand the text is not clear enough to activate the schemas needed, they would not guess the meanings of the words correctly. This exactly proves the first two possibilities of not understanding a text (Rumelhart,1977), that is, without a proper schema, a reader cannot understand a text; even with the proper schemas, a reader might fail to understand the text for the author doesn't provide enough clues for readers to activate the schemas that the reader has.

The above experiment gives us the following instructions in English reading teaching:

(1) Since the reader's reading comprehension can be influenced by the content schemas, the reading materials the teachers choose should not be so rare for the students in case the students should fail to understand the text due to lack of the corresponding schemas. And the contents of the text, on the other side, should not be so familiar to the students, for this is of no significance in promoting the students' reading comprehension. This instruction also works in designing the reading paper in English examination.

(2) Teachers should provide some pre-reading questions about the background etc. of the texts to help to activate the corresponding schemas in the mind of the students. What's more, teachers should give students suggestion on the implied sense of the text to help them to link to their existing schemas; and after finishing reading, teachers may organize the students to discuss about the answers and the text to strengthen their newly-built schemas, which might be utilized in their future reading. 
(3) The students should wide their knowledge to build up more schemas to help them deal with the texts with different contents and increase their reading fluency.

\section{CONCLUSION}

Although the study has proved the guiding function of the schemas, there are still deficiencies in the experiment. For example, the design of the questions and the arrangement of the class teaching are only on the superficial level; further study about the influence of the formal schemas on reading needs to be done. However, this teaching method utilizing schema theory has broken through the traditional teacher-centered approach with which the teachers explain the words and grammar while the students are in a negative position only listening to the teachers and has placed the teachers in an auxiliary guiding position.

\section{REFERENCES}

[1] Anderson, Neil J (2000). Individual Differences in Strategy Use in Second Language Reading and Testing. The Modem Language Journal 75(2): 92-93

[2] Barnett, Marva A (1989). More than Meets Eye: Foreign Language Learner Reading: Theory and Practice. Englewood Cliffs, N. J.:Prentice Hall Regents.

[3] Carrell, P.L. \& Eisterhold, T.C. (1983). Schema Theory and EFL Reading Pedagogy, TESOL Quarterly 17 (4):82.

[4] Eskey, D.E. (1988). Holding in the Bottom: an Interactive Approach to the Language Problems of Second Language Readers in Carrell, P.L., Devine, J. and Eskey, D.E. (eds) (1988) Interactive Approaches to Second Language Reading. Cambridge: CUP.97.

[5] Goodman, K.S. Reading. (1967). A Psycholinguistic Guessing Game.Journal of the Reading Specialist, 6(1):126-35.

[6] Goodman, K. (1975). The Reading Process in Carrell, P.L., Devine, J. and Eskey, D.E. (eds) (1988) Interactive Approaches to Second Language Reading. Cambridge: CUP.12.

[7] Gough, P. B. (1972). One second of reading. In H. Singer, \& R. B. Ruddell (Eds.), Theoretical Models and Processes of Reading, $3^{\text {rd }}$ edition. Newark, Delaware: International Reading Association. 661-686.

[8] Nunan, D (1999). Second Language Teaching and Learning. Bosten: Heinle \& Heinle. 83-85.

[9] Nuttal, C. (2000). Teaching Reading Skills in a Foreign Language, London: Heinemann Educational Books.

[10] Scovel, T. (2000). Psycholinguistics, Shanghai: Shanghai Foreign Language Press.

[11] Rumelhart, D. (1977). Schemata: The building blocks of cognition. In Theoretical issues in reading comprehension. R. Spiro, B. Bruce and W. Brewer. Hillsdale, N.J.: Lawrence Erlbaum Associates. 88-96.

[12] Thorndike and Edward Lee. (1971). The Human Nature Club: An Introduction to the Study, Montana: Kessinger Publishing.

[13] Zhao Yanfang. (2001). An Introduction to Cognitive Linguistics, Shanghai: Shanghai Foreign Language Education Press.

Yunning Che, was born in Qingdao, China in 1978. She received her Master's Degree in linguistics from Ocean University of China in 2006.

She is currently a lecturer in the English Department, School of Foreign Languages, Qingdao University of Science and Technology, China. Her research interests include SLA, cognitive linguistics. 